\title{
Empirical Correlation of CNDO/2 and Extended Hückel Ionization Energies for the Azines
}

\author{
BJØRN BIRKNES and KNUT FEGRI, JR.
}

Department of Chemistry, University of Bergen, N-5014 Bergen-University, Norway

Empirical corrections to orbital energies from CNDO/2 and Extended Hückel calculations for benzene are used in an attempt to calculate ionization energies of the azines. Some experimental tendencies are reproduced but the results are markedly inferior to those obtained by the same technique using ab initio wavefunctions.

Koopmans' theorem makes possible relatively simple calculations of molecular ionization energies but does not always give sufficient accuracy for the assignment of photoelectron spectra. For the azines, Koopmans' theorem seems to give the wrong ordering of ionization energies for $n$ and $\pi$ orbitals. Almlöf et al. ${ }^{1}$ have performed $a b$ initio calculations for benzene and the azine series adding empirical corrections to the calculated energies. These corrections were obtained for each orbital with a photoelectron line of definite assignment, in general from the benzene assignment by Lindholm et al. ${ }^{2}$ With a "topological" classification of the orbital symmetries these corrections could be transferred also to the other molecules. The resulting assignment of the azines was in essential agreement with the work of Gleiter et $a l .^{3}$

It is well known that semi-empirical MO methods often introduce additional inaccuracies to those caused by Koopmans' theorem, and in their standard versions they are not accurate enough for the direct assignment of the azines. ${ }^{4,5}$ Still, one may ask whether the procedure of Almlöf et al., gauged to the benzene photoelectron spectrum might not give useful results for the azines. The present note shows this not to be the case using standard $\mathrm{CNDO} / 2$ and Extended Hückel wavefunctions.
Thus, we have first estimated the differences between experimental and calculated ionization energies for benzene using Koopmans' theorem and the assignment by Lindholm and coworkers. ${ }^{2}$ We have then classified the orbitals of the azines according to the topological scheme of Almlöf et al. and assumed that the same corrections to Koopmans' theorem apply for each orbital in the azines as in benzene.

The classification scheme of Almlöf et al. is based upon an idealized cylinder symmetry $\left(D_{\infty h}\right)$. Orbital labels are of the form $n A_{\mathrm{p}}$, where $n$ is a "principal quantum number" describing node planes encircling the cylinder symmetry axis ( $n=1$, no node plane; $n=2$, one plane, etc.), and $A$ is an "angular" quantum number used for nodes passing through the cylinder axis (orbitals with $0,1,2$, and 3 such planes are labelled $S, P, D$, and $F$ ). The subscript indicates inversion symmetry ( $\mathrm{g}$ for symmetric and $u$ for antisymmetric orbitals).

Apart from benzene, the molecules considered are all nitrogen heterocycles which may be notionally derived from benzene by the successive replacement of $\mathrm{CH}$-groups by nitrogen: pyridine has one $\mathrm{N}$-atom, pyridazine, pyrimidine, and pyrazine two $\mathrm{N}$-atoms, 1,3,5triazine three $\mathrm{N}$-atoms and 1,2,4,5-tetrazine four $\mathrm{N}$-atoms. All molecules are planar and have 30 valence electrons and consequently 15 occupied valence molecular orbitals, counting degenerate orbitals separately.

\section{RESULTS}

Table 1 shows the calculated and the observed ionization energies for benzene. For $\mathrm{CNDO} / 2^{\circ}$

Acta Chem. Scand. A 29 (1975) No. 6 
Table 1. Experimental and calculated (Koopmans' theorem) ionization energies of benzene (eV).

\begin{tabular}{|c|c|c|c|c|c|}
\hline Orbital & $\begin{array}{l}\text { Experi- } \\
\text { mental }\end{array}$ & $\mathrm{CNDO} / 2$ & Diff. & $\begin{array}{l}\text { Extended } \\
\text { Hückel }\end{array}$ & Diff. \\
\hline $\begin{array}{l}\sigma \text { orbitals } \\
1 S_{\mathrm{g}} \\
1 P_{\mathrm{u}}^{\prime}, 1 P_{\mathrm{u}}^{\prime \prime} \\
1 D_{\mathrm{g}}^{\prime}, 1 D_{\mathrm{g}}^{\prime \prime} \\
2 S_{\mathrm{g}} \\
1 F_{\mathrm{u}}^{\prime} \\
1 F_{\mathrm{u}}^{\prime \prime \prime} \\
2 P_{\mathrm{u}}^{\prime}, 2 P_{\mathrm{u}}^{\prime \prime \prime} \\
2 D_{\mathrm{g}}^{\prime}, 2 D_{\mathrm{g}}^{\prime \prime \prime}\end{array}$ & $\begin{array}{l}25.9 \\
22.7 \\
19.1 \\
16.9 \\
14.9 \\
15.6 \\
14.1 \\
11.8\end{array}$ & $\begin{array}{l}51.2 \\
38.0 \\
30.5 \\
29.3 \\
21.7 \\
20.0 \\
19.3 \\
14.4\end{array}$ & $\begin{array}{r}-25.3 \\
-15.3 \\
-11.4 \\
-12.4 \\
-6.8 \\
-4.4 \\
-5.2 \\
-2.6\end{array}$ & $\begin{array}{l}26.9 \\
23.7 \\
18.9 \\
16.2 \\
13.7 \\
16.5 \\
14.4 \\
12.8\end{array}$ & $\begin{array}{r}-1.0 \\
-1.0 \\
0.2 \\
0.7 \\
1.2 \\
-0.9 \\
-0.3 \\
-1.0\end{array}$ \\
\hline $\begin{array}{l}\pi \text { orbitals } \\
1 S_{\mathrm{u}} \\
1 P_{\mathrm{g}}^{\prime}, 1 P_{\mathrm{g}}^{\prime \prime}\end{array}$ & $\begin{array}{r}12.2 \\
9.3 \\
\end{array}$ & $\begin{array}{l}23.6 \\
14.1 \\
\end{array}$ & $\begin{array}{r}-11.4 \\
-4.8 \\
\end{array}$ & $\begin{array}{l}13.9 \\
12.3 \\
\end{array}$ & $\begin{array}{l}-1.7 \\
-3.0 \\
\end{array}$ \\
\hline
\end{tabular}

the difference between these quantities is greatest for the innermost orbitals. This is to be expected from the known errors of Koopmans' theorem but is due mainly to the choice of parameters as may be seen by comparison with the $a b$ initio calculations of Almlöf et al. ${ }^{1}$ For the Extended Hückel method ${ }^{7}$ ionization energy corrections are much smaller, especially for the $\sigma$ orbitals.

The ionization energies from CNDO/2 calculations using Koopmans' theorem change relatively little with increasing nitrogen content, a result which is unchanged by the empirical corrections taken from benzene. The photoelectron spectra, however, show increasing ionization energies with nitrogen substitution. After correction the deviations between observed and calculated ionization energies using CNDO/2 lie within $1.1 \mathrm{eV}$ for pyridine, within $1.8 \mathrm{eV}$ for the diazines and within $2.2 \mathrm{eV}$ for 1,3,5-triazine. Exceptions are found for one level each of pyridazine, pyrazine, and 1,3,5triazine. Even larger deviations are obtained for 1,2,4,5-tetrazine.

With the Extended Hückel method the agreement between orbital energies and ionization energies is better and the same is true for the results after correction. With one or two exceptions for each molecule the results are within $0.6 \mathrm{eV}$ for pyridine, and within $1.3 \mathrm{eV}$

Table 2. Calculated and experimental ionization energies of pyridine and pyrazine. The calculated results are obtained using Koopmans' theorem corrections for benzene ( $\mathrm{VV})$.

\begin{tabular}{|c|c|c|c|c|c|c|c|c|}
\hline & $\begin{array}{l}\text { Pyridine } \\
\text { CNDO/2 }\end{array}$ & EH & $\mathrm{AI}$ & Exp. & $\begin{array}{l}\text { Pyrazine } \\
\text { CNDO/2 }\end{array}$ & EH & $\mathbf{A I}$ & Exp. \\
\hline $1 S_{\mathrm{g}}$ & 26.4 & 28.3 & 29.2 & - & 26.6 & 28.9 & 30.7 & - \\
\hline$I P_{\mathrm{u}}^{\mathrm{g}}$ & 22.2 & 22.7 & 23.2 & 23.3 & 21.7 & 22.7 & 24.0 & 24.0 \\
\hline $1 P_{\mathrm{u}}^{\mathrm{u}}{ }^{\prime \prime}$ & 24.0 & 24.1 & 24.8 & 24.2 & 25.2 & 27.0 & 28.6 & - \\
\hline $1 D_{\mathrm{g}}^{\mathrm{u}}$ & 19.1 & 19.4 & 19.6 & 19.6 & 19.0 & 19.7 & 20.5 & 20.6 \\
\hline $1 D_{\mathrm{g}}^{\mathrm{g} / \prime}$ & 19.7 & 19.5 & 19.8 & 20.0 & 20.2 & 20.2 & 21.2 & 21.0 \\
\hline $2 S_{\mathrm{g}}^{\mathrm{g}}$ & 16.3 & 16.8 & 17.0 & 17.1 & 15.4 & 17.0 & 17.2 & 17.1 \\
\hline $1 F_{\mathrm{u}}^{\mathrm{g},}$ & 15.6 & 16.1 & 15.8 & 15.7 & 16.2 & 16.5 & 17.0 & 17.0 \\
\hline $1 F_{\mathrm{u}}^{\mathrm{u}}{ }^{\prime \prime \prime}$ & 16.0 & 15.6 & 15.7 & 15.7 & 16.6 & 15.5 & 16.4 & 16.2 \\
\hline $2 P_{\mathrm{u}}^{\mathrm{u}}$ & 13.7 & 14.0 & 14.5 & 14.4 & 13.4 & 13.9 & 15.0 & 15.0 \\
\hline $2 P_{\mathrm{u}}^{\mathrm{u}}{ }^{\prime \prime}$ & 13.1 & 14.2 & 13.8 & 13.7 & 11.7 & 14.1 & 11.4 & 11.7 \\
\hline $2 D_{\mathrm{g}}^{\prime \prime}$ & 12.1 & 12.1 & 12.6 & 12.5 & 12.6 & 13.1 & 13.6 & 13.3 \\
\hline $2 D_{\mathrm{g}}^{\mathrm{g}}$ & 10.7 & 11.3 & 9.6 & 9.7 & 10.1 & 11.0 & 9.4 & 9.4 \\
\hline $1 S_{\mathrm{u}}^{\mathrm{g}}$ & 12.4 & 13.4 & 12.9 & 13.2 & 12.4 & 13.7 & 13.9 & 14.0 \\
\hline $1 P_{\mathrm{g}}^{\prime}$ & 9.3 & 9.2 & 9.5 & 9.7 & 9.3 & 9.2 & 10.0 & 10.2 \\
\hline $1 P_{\mathrm{g}}^{\mathrm{g}}$ & 9.9 & 10.1 & 10.4 & 10.5 & 10.3 & 11.7 & 11.8 & 11.4 \\
\hline
\end{tabular}

Acta Chem. Scand. A 29 (1975) No. 6 
for the diazines. For 1,3,5-triazine and 1,2,4,5tetrazine the deviations are within $1.9 \mathrm{eV}$.

The order of ionization energies, after correction, is in essential agreement with experiment and with the ab initio calculations for the inner valence orbitals. This is an expected result since it is also obtained with the Extended Hückel method directly. ${ }^{8}$ Notable deviations, however, are obtained for the outermost orbitals. Even after correction the semiempirical wavefunctions fail to predict the correct ordering of $\sigma$ and $\pi$ states. The lowest $\sigma$ ionization energy, conventionally related to a nitrogen lone-pair is systematically stabilized relative to the $\pi$ orbitals, leading to erroneous assignements for the first ionization energy for all azines except, possibly, for pyridine. Representative results for pyridine and pyrazine are given in Table 2. The ab initio results as well as the experimental assignments are from Almlöf et al.,1 the latter in essential agreement with the work of Gleiter et al. ${ }^{3}$

The systematic increase of the deviations with increasing nitrogen substitution may be interpreted as due to non-optimal nitrogen parameters relative to those of carbon and hydrogen. A reparametrization might therefore give some improvement.

The conclusion of the present study is that the utility of the approach of Almlöf et al. in assigning photoelectron spectra of series of similar molecules with conventional semiempirical wavefunction is limited.

Acknowledgements. This work was supported by a grant from the Norwegian Research council for Science and the Humanities. Thanks are due to professor Rolf Manne who instigated this project.

\section{REFERENCES}

1. Almlöf, J., Johansen, H., Roos, B. and Wahlgren, U. J. Electron Spectrosc. Relat. Phenom. 2 (1973) 51.

2. Jonsson, B. Ö., Lindholm, E. and Skerbele, A. Int. J. Mass Spectrom. Ion Phys. 8 (1972) 101 .

3. Gleiter, R., Heilbronner, E. and Hornung, V. Helv. Chim. Acta 55 (1972) 255.

4. Ellis, R. L., Jaffé, H. H. and Masmamdes, C. A. J. Amer. Chem. Soc. 96 (1974) 2623.

5. Palmer, M. H., Gaskell, A. J. and Findlay, R. H. Tetrahedron Lett. 47 (1973) 4659.

6. Pople, J. A. and Segal, G. A. J. Chem. Phys. 44 (1966) 3289.
7. Hoffmann, R. J. Chem. Phys. 39 (1963) 1397.

8. Friedh, C., Åsbrink, L., Jonsson, B. Ö. and Lindholm, E. Int. J. Mass. Spectrom. Ion Phys. 8 (1972) 101.

Received February 10, 1975. 